MEHRZAD EBRAHEMZADIH, T.A., ${ }^{1,2}$

(Corresponding Author)

E-mail: emhrzad@yahoo.com

OMID GIAHI, Ph.D.1,2

E-mail: omidgi71@yahoo.com

FARSHAD FOROGINASAB, M.Sc. ${ }^{3}$

E-mail: farzad442@yahoo.com

${ }^{1}$ Environmental Health Research Center

Kurdistan University of Medical Sciences

Sanandaj, Iran

2 Department of Occupational Health, Faculty of Health

Kurdistan University of Medical Sciences

Pasdaran Avenue, Sanandaj, Iran.

${ }^{3}$ Shahid Behshti University of Medical Sciences

Evin, Tehran, Iran
Safety and Security in Traffic

Review

Submitted: Jan. 18, 2015

Accepted: Feb. 4, 2016

\title{
ANALYSIS OF TRAFFIC ACCIDENTS LEADING TO DEATH USING TRIPOD BETA METHOD IN YAZD, IRAN
}

\begin{abstract}
This study tried to find the original causes of road accidents to prevent their occurrence. This was a descriptive-analytic retrospective study which assessed 1,000 cases of road accidents leading to death during 2003-2013 using the Tripod Beta method. The latent problems, the contributing preconditions, and corrective strategies for the prevention of occurrence of these accidents were determined. The findings of this study revealed that violation of traffic safety rules, especially deliberate violations and risk-takings decreased with increasing age. In comparative status of the superficial problems, illegal and impermissible speed of drivers accounted for $19.10 \%$, in comparative status of preconditions, violation of safety rules accounted for $32.6 \%$ and finally, in comparative status of the latent problems, the presence of financial constraints and time pressure in designing and manufacturing of the cars, and quality of city streets, roads, accounted for $20.1 \%$, of the leading causes of occurrence of accidents in this study.
\end{abstract}

\section{KEY WORDS}

original causes; traffic accidents; Tripod Beta;

\section{INTRODUCTION}

Today, the promotion of public health is one of the fundamental components of reinforcement of the course of stable development since the healthy human is the axis of stable development [1]. Road traffic accidents are a major source of public health concern in Iran. Road traffic system is the most complicated and the most dangerous one among the various systems encountered every day obligatorily by members of the community, so that about 1.2 million individuals are scarified and 50 million more are hurt annually in road accidents. It has been speculated that these figures will increase by $65 \%$ during the next 20 years unless some innovative prevention measures are taken [2]. The results of some studies conducted so far have demonstrated that $98 \%$ of accidents may be avoided [2,3]. Road traffic accidents are a major cause of death and disability globally, with a disproportionate number occurring in developing countries [3]. Road accidents induce psychosomatic injuries on the one hand, and cause the wastage of capital and economic damage, on the other [4]. Our country ranks first in the incidence of road accidents so that more than 17,000 individuals are killed annually in road accidents [5]. Road accidents account for $30 \%$ of the total incidents in Iran. According to World Health Organization (WHO) statistics, Iran is ranked first in the world regarding the driving accidents. Iran has the highest rate of road accidents in the world. According to a report published by WHO in 2007-2008 road traffic fatalities 22,918 (80\% males, 20\% females) per year and 685,611 non-fatal road traffic injuries were reported [6]. Every year, according to the statistics, 1.2 million people are known to die in road accidents worldwide. Millions of others sustain injuries, with some suffering permanent disabilities. More than half the people killed in traffic crashes are young adults aged between 15 and 44 years - often the breadwinners in a family [2]. Montazeri et al. reported that between March 1999 and 2000 a total of 15,482 individuals died in road traffic accidents in Iran [7]. Statistics provided in Iran indicates that road accidents rank second after the cardiovascular diseases as the first cause of mortality of all age groups and the age group $\leq 40$ years in Iran. More than 400 thousand traffic accidents occur in Iran annually ranking this country first in mortal accidents around the world and leaving thousands of 
casualties in the urban and suburban roads [8]. The global Losses due to road traffic injuries are estimated at 518 billion dollars; more than the total amount that these countries receive in development assistance $[2,9]$. An accident comprises a sequential course of events, each of which can be considered separately in its own turn as a distinguished cause. Since the time of appearance of safety principles and the emergence of this important science, the safety experts have always tried to investigate the manner of the occurrence and the real nature of emergence of events. Nowadays, the nature and way of incidence of events can be perceived by considering accidents as a structure and as a hierarchical event [10]. This is why innovative theories have emerged regarding incidents and their contributory factors. In Tripod Beta method, the paths of causes of incidence of an accident (from the direct to the original or radical cause) are demonstrated for each event. This theory is based on the premise that an incident always consists of a series of events with several causes. Among the causes of traffic accidents are unsafe transportation routes, people's inappropriate culture of vehicle use, deviation to the left side of the road, lack of observation of priority of passing, insufficient attention to the front, low safety index of vehicles, lack of concentration in driving, etc. [11]. The superficial problems like unsafe acts considered in Tripod Beta do not occur separately, they are rather affected by a series of external factors or preconditions, originating themselves from a series of latent problems. These latent problems, in turn, originate from decisions or actions performed by designers, planners, programmers, and managers [12]. The superficial problems are those which are in close contact with incidence of an event. The preconditions are the systemic, mental, psychological, positional, and/or environmental states which directly lead to superficial errors. The latent problems are abnormal conditions creating the preconditions and leading to superficial problems. The latent problems which have the potential for creating events may be hidden for long periods of time and display themselves only under the conditions of the creation of normal suitable conditions such as combination with some preventive factors, superficial problems, technical errors, or the unusual states of the system $[11,12]$. In any system there must be a proper management to control the risks. The incidence of an accident means that there has not been any appropriate management for controlling risks and dangers and that managerial controls have not been applied. When an accident happens, this indicates that the last controlling cycle for removing the risks has been defective and thus has been unable to prevent the incidence of the said accident. Consequently, it is mandatory in assessing accidents to investigate and analyze all the lost cycles and the defects of the control and management systems. The progressive achievements in information technology, communication, and human knowledge have predisposed to the application of practical measures for decreasing the rate of traffic accidents and acculturation of safe driving [13]. Hence, this study is aimed at determining the original and radical causes of the past accidents to analyze them and provide and apply engineering strategies for reducing mortalities and casualties, and also the imposed costs of road accidents.

\section{MATERIALS AND METHODS}

This retrospective study investigated 1,000 cases of traffic accidents leading to death using the mortality statistics in the Statistics Department of Health Deputy of Shahid Sadoughi University of Medical Sciences in Yazd, central Iran, during 2003-2013. It assessed and analyzed the causes, sequence, and effects of incidence of events using Tripod Beta, and then the original causes, preconditions, and the contributing factors of these accidents were determined. It is noteworthy that to determine the effects of human errors in decision making and the incidence of accidents, a two-part questionnaire was used first. The first part included demographic information and data on driving and history of driving accidents of drivers over the past 10 years. The second part of the questionnaire included human errors using the standardized questionnaire of Drivers' Behavioral Study on 1,000 drivers with a history of at least one accident. The frequency of influential effective human errors in road accidents, distribution of errors and the role of each type of error in the quality and severity of traffic accidents were determined using statistical analyses and the results were analyzed using SPSS18 (Statistical Package for the Social Sciences version 18).

\section{RESULTS}

Of 1,000 traffic accidents studied in this research, 693 cases occurred on urban roads and 307 cases occurred on suburban roads and highways. The total number of fatal accidents during the years studied was 1,412 persons. The mean age of drivers involved in accidents was $36.5 \pm 3.66$ years and the mean of driving experience of colliding drivers was $15.56 \pm 4.66$ years. It should be mentioned that 318 drivers had no history of previous accidents over the recent 10 years. Also, 486 drivers experienced at leas one or two accidents over the past 10 years. Further, 226 drivers experienced more than two accidents over the past 10 years. Figure 1 demonstrates the comparative status of preconditions of traffic accidents in this study using the Tripod Beta method. 


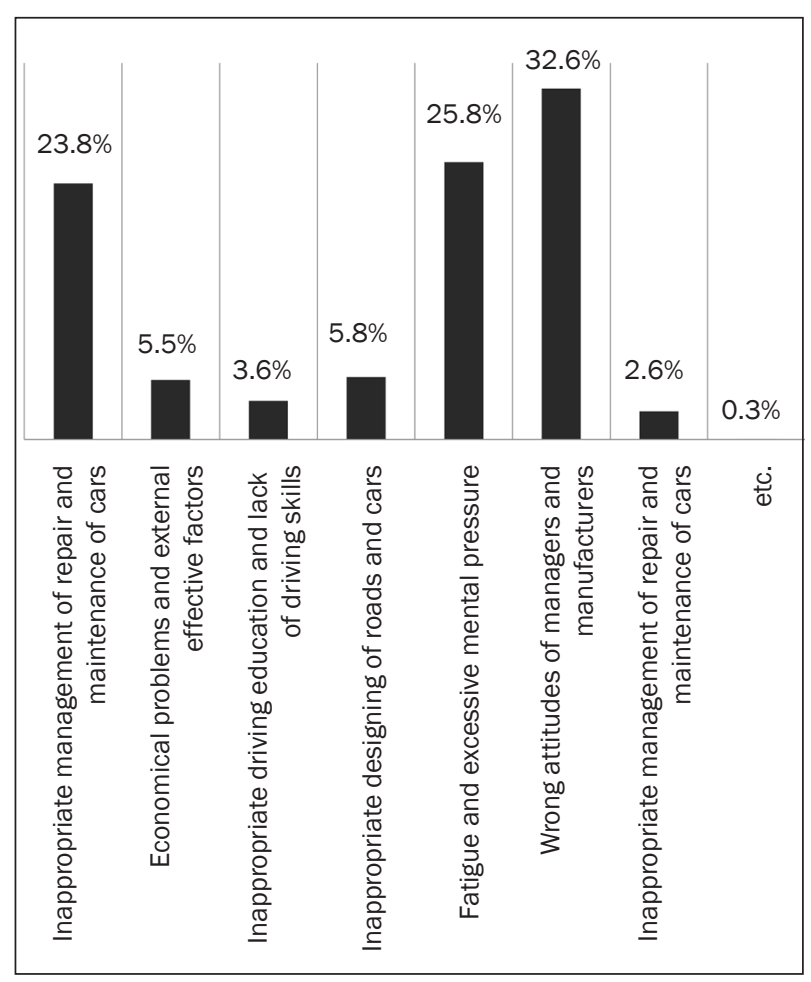

Figure 1 - Comparative status of preconditions creating traffic accidents

Our findings indicated that in this study, 84 preconditions of incidence of superficial problems contributing to the occurrence of traffic accidents were identified mostly including lack of observation of safety rules and regulations with $32.6 \%$, followed by exhaustion and excessive mental pressure with $25.8 \%$ of all preconditions as the main causes of road accidents. Table 1 presents the status of quality control of the colliding cars in terms of manufacturing year indicating a direct and significant correlation between the amount of functioning years of the car and accidents.

Table 1 - Status of damaged cars regarding functioning duration

\begin{tabular}{||c|c|c||}
\hline $\begin{array}{c}\text { Functioning } \\
\text { duration }\end{array}$ & $\begin{array}{c}\text { Number of } \\
\text { damage cars }\end{array}$ & p-value \\
\hline \hline 0-5 years & 416 & $(0.001 \leq \mathrm{p}$-value $)$ \\
\hline 5-10 years & 266 & $(0.001 \leq \mathrm{p}$-value $)$ \\
\hline Over 10 years & 318 & $(0.001 \leq \mathrm{p}$-value $))$ \\
\hline
\end{tabular}

Moreover, this study suggested that 95 superficial problems of traffic accidents have been found mostly including first, illegal speed of the colliding drivers with $19.10 \%$, and second, absent-mindedness and carelessness of the colliding drivers with $16.8 \%$ (Figure 2).

A total of 76 original and latent problems predisposing to accidents leading to death were identified in this study. Of these, the presence of financial constraints and time pressure in designing and manufacturing of the cars, and urban and suburban roads with $20.1 \%$ played the greatest part in the creation of preconditions for the incidence of accidents followed by unavailability of equipment and low quality of car

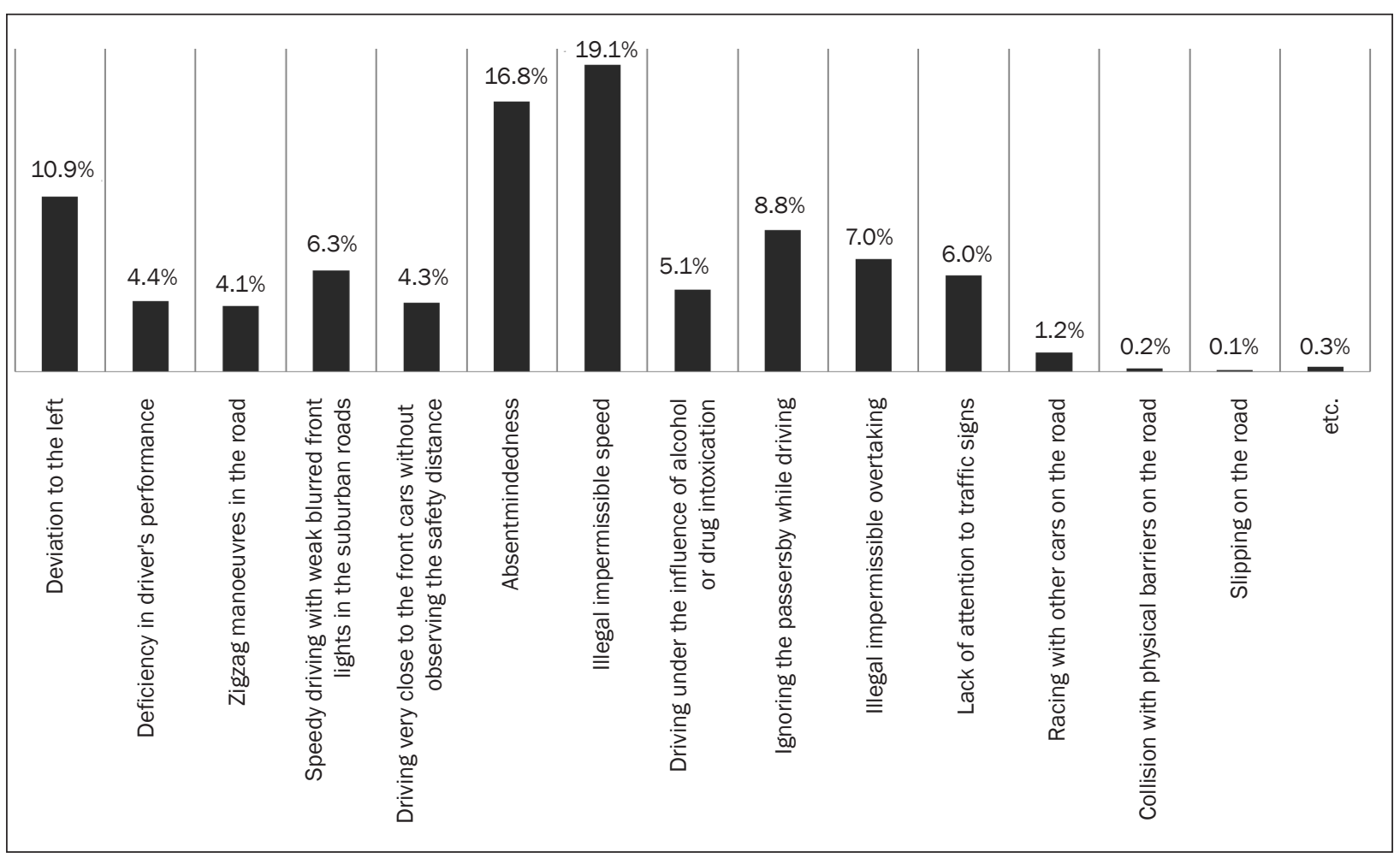

Figure 2 - Comparative status of superficial problems leading to traffic accidents 
equipment with $15.5 \%$ playing a part in the creation of preconditions contributing to accidents (Figure 3).

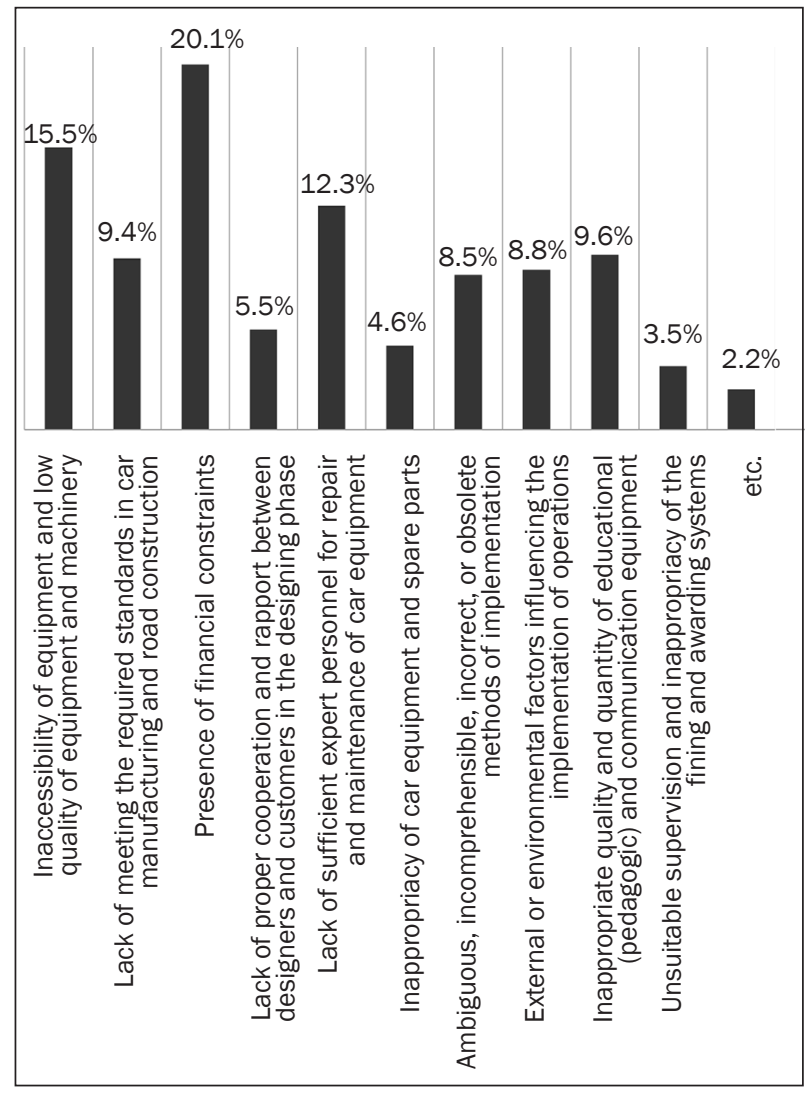

Figure 3 - Comparative status of latent problems leading to traffic accidents

Table 2 - Demographic variables of drivers

\begin{tabular}{||l|c|c||}
\hline \multicolumn{1}{||}{ Variables } & Mean & $\begin{array}{c}\text { Standard } \\
\text { Deviation } \\
\text { (SD) }\end{array}$ \\
\hline \hline Age & 38.4 & 5.66 \\
\hline Driving license history & 15.93 & 4.11 \\
\hline Driving experience & 18.12 & 3.05 \\
\hline Mean of average speed of driving & 83.54 & 12.26 \\
\hline Maximum speed & 98.73 & 15.6 \\
\hline Diurnal driving hours & 9.46 & 4.12 \\
\hline
\end{tabular}

P-value $<0.05$
Table 2 shows the Demographic variables of drivers in this study. Moreover, the findings of this study showed that the rate of deliberate violation of traffic rules and risks decreased with increasing age. There was a significant reverse correlation between the amount of driving per year and various items of deliberate and undeliberate rules violations and ignorance (Table 3). This means that the greater the amount of driving and the longer the route, the less the rate of errors and rule violations. This may be attributed to greater wisdom and understanding, more patience, and concern with post-accident consequences among older drivers. The speed of driving was directly and significantly correlated with the rate of rules violations and accidents meaning that the increased speed resulted in increased risks and rules violations.

Table 4 - Mean and standard deviation (SD) of different types of driving errors

\begin{tabular}{|l|c|c||}
\hline \multicolumn{1}{|c|}{ Variables } & Mean & $\begin{array}{c}\text { Standard } \\
\text { Deviation } \\
\text { (SD) }\end{array}$ \\
\hline \hline Deliberate rules violation & 28.17 & 7.71 \\
\hline Undeliberate rules violations & 5.33 & 1.52 \\
\hline Mistakes and errors & 15.36 & 4.14 \\
\hline Forgetfulness & 30.85 & 7.44 \\
\hline
\end{tabular}

As Table 4 shows, the rate of ignorance and deliberate rules violations is greater than other items. Ignorance refers to actions committed by individuals due to lack of awareness of their consequences or their commitment. The high rate of this item is due to the fact that driving is among the professions which demand high wisdom, understanding, sensibility, concentration, and patience.

The deliberate rules violations could be classified as the following: illegal speed and overtaking, not fastening the safety belt, not allowing other cars to pass by, zigzag movements, deliberately ignoring the car speed, getting mad at other drivers and trying to follow other drivers angrily, passing through red light, talking on the cell phone, and many other items.

Table 3 - Status of the association between demographic variables and various types of driving errors

\begin{tabular}{||l|c|c|c|c||}
\hline \multicolumn{1}{|c|}{ Variables } & $\begin{array}{c}\text { Deliberate rules } \\
\text { violation }\end{array}$ & $\begin{array}{c}\text { Undeliberate rules } \\
\text { violations }\end{array}$ & Mistakes and errors & Forgetfulness \\
\hline \hline Age & 0.002 & 0.085 & 0.04 & 0.05 \\
\hline Driving experience & 0.003 & 0.028 & 0.06 & 0.065 \\
\hline Diurnal driving hours & 0.049 & 0.075 & 0.072 & 0.052 \\
\hline Amount of driving per year & 0.0009 & 0.029 & 0.0008 & 0.027 \\
\hline Maximum speed & 0.001 & 0.0004 & 0.004 & 0.002 \\
\hline P-value $<0.05$
\end{tabular}




\section{DISCUSSION}

The conclusions and results are valid only for Iran and cannot be applied in other countries. Road accidents are a social phenomenon in Iran requiring the identification of its more fundamental dimensions including the cultural, psychological, sociological, propagandistic, judicial, and medical issues, and the role and position of police in addition to other shortcomings and failures due to technology, such as the quality of streets and roads, and the low quality of car manufacturing [14]. Definitely, the number of handicapped and casualties of traffic accidents is 10 to 15 times greater than the number of the related mortalities with its irreparable consequences such as getting helpless without any support, the mental and psychological problems, the extremely back-breaking therapeutic expenses, and also the penal and judicial issues. Many dangerous road accidents happen yearly in Iran pushing many people towards death and subsequently, leaving many families helpless without any support [15]. More than $90 \%$ of mortalities occur in low-income and moderate-income countries in Africa and Middle East. This is the case although these countries possess only half of the world's vehicles [16]. Moreover, age of persons is one of the factors that may affect the culture of driving. In fact, driving in very young age may be very dangerous. That is why the age of obtaining a driving license is set at +18 years in many countries. Of course, there are no specific measures and interventions for driving by the aged. As it appears, the causes of many accidents are the elderly drivers who are not capable of safe driving and are not able to react quickly and appropriately in many critical situations due to their old age. In the study by Mesken et al., more than 30\% of the mortalities and casualties of road accidents were children and the young below 25 years of age and in the young drivers group, the young men below 25 years sustained accidents three times more than others. This is consistent with the finding that there is a reverse correlation between increasing age and the incidence of rules violations and road accidents [17]. Furthermore, the study by Zhou et al. conducted in China, reported the highest rate of drivers' mortality among the 18-30-year age group followed by 31-40year age group which is very similar to our finding in this study [18]. The study by Norris found that inexperience in driving has a high prevalence among the youth. This is the case why the inexperienced groups are very dangerous drivers. It was also observed that driving drowsily decreased with increasing experience which is consistent with our results [19]. Speed has been always considered as the leading cause of road accidents around the world. In this respect, attention should be given more to driving education and pedagogy and various educational methods should be applied. Speed of a car is considered illegal and impermissible when it violates the speed limits of the road, increasing the incidence of traffic accidents. Our findings also indicated the direct correlation between increased risks and rules violations with increased car speed during driving. Furthermore, illegally high speed is one of the most primary and most direct causes of incidence of mortal road accidents, this being consistent with the findings of other researchers [20]. According to the study conducted by Mohammadfam on accidents leading to death in chemical industries in 2009, the application of fining and awarding systems, and also promotion of informational and educational level to remove the latent problems and preconditions are rendered as suitable [12]. Our study also recommends the creation of fining and awarding systems on urban and suburban roads and highways for preventing deliberate and undeliberate rules violations. Absence of observation of traffic safety rules and regulations is considered as the most fundamental precondition of rules violation and risk-taking behaviours which cause accidents leading to death. This finding is consistent with the results of the study conducted in Yasooj in Iran [21]. According to the study conducted by Iversen et al., most of the accidents leading to death in this study (more than 50\%) happened between 9 p.m. and 5 a.m. indicating the effect of drowsiness, exhaustion, and fatigue on the quality of driving of drivers on the roads. This reveals that fatigue and mental pressure are among the most basic and direct causes of incidence of mortal accidents, this being proved by the results of other researchers [22]. Shruthi et al., reported that Maximum Road traffic accidents occurred during the daytime, between 6 a.m. to 12 p.m. and greater number of accident cases 117 (52\%) occurred in winter [23]. Most of the patients were drivers under 35 years of age. There were $67 / 100$ road traffic accidents that occurred over the weekend (Friday-Sunday); nearly 60\% between 24:00-09:00 hrs; on non-weekend days about $80 \%$ of road traffic accidents were recorded between 14:00-24:00 hrs, With the blood alcohol content test and urine test for drugs detection 43/100 patients showed a single or multiple positivity [24]. According to the study conducted by Dipak Kumar Das in Barpeta - India, the maximum number of Road traffic accident cases $(48.35 \%)$ was reported to occur between 12 noon to 6 p.m. and the maximum number of Road traffic accident cases (33.52\%) occurred in winter due to slipping on the road [25]. Persons exhausted by long driving lose their patience, and the rate of their concentration and reaction speed index decrease [26]. By surveying various cases of accidents, it was concluded that the main cause of many of them is drowsiness and fatigue due to long-distance driving. Speed of driving is one of the issues which is considered as the main cause of many accidents not only in our country, but also in many countries of the world. Countries of the world have been always seeking strat- 
egies to control speed, and committed themselves to many actions. Iran has recently applied new methods as the use of plastic puddles, insensible police control, etc. to prevent accidents occurring due to illegally high speed. In the case when an individual commits such rule violation, such as overtaking from the right side, sudden left deviation, racing with other cars, and performing zigzag movements, they not only put themselves in a challenging situation, but also push other drivers towards dangerous accidents. Hence, noticing this type of drivers and keeping them under close vigilance should be among the first priorities of the traffic police.

\section{CONCLUSION}

The main conclusion of this project is that a great number of drivers see no necessity to commit themselves to observation of traffic safety rules and that most violations of the rules occur either deliberately or due to ignorance and carelessness. A general examination of the issue reveals that les than $5 \%$ of our community commit the deliberate violation of safety rules and also violations with definite risk and determined hazards. Eventually, regarding the daily increase in the rate of accidents, it is advisable that more studies be conducted in future on environmental, social, economical, and cultural issues contributing to road accidents. Obviously, administrators, nurses, and staff of health centres can play a great role in this regard.

\section{ACKNOWLEDGEMENT}

The authors would like to thank the Statistics Department of Health Deputy of Yazd University of Medical Sciences for their assistance with data collection and interpretation.

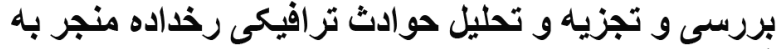

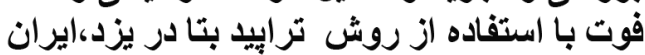

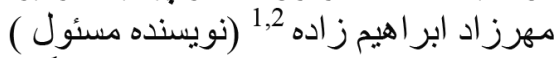

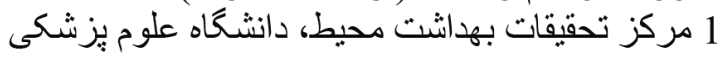

$$
\begin{aligned}
& \text { كردستان، سنندج، اير ان. }
\end{aligned}
$$

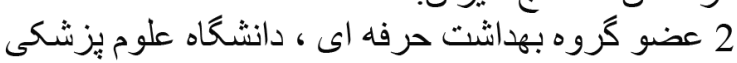

$$
\begin{aligned}
& \text { كردستان، سنند ج، اير ان. } \\
& \text { 1مركز تحقيقات بهداشت محيط، دانشگاه علوم يزشكى } \\
& \text { كردستان، سنندج، اير ان. }
\end{aligned}
$$

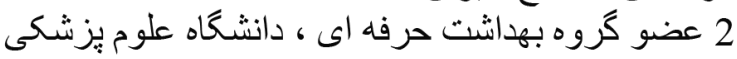

$$
\begin{aligned}
& \text { كردستان، سنندج، اير ان. }
\end{aligned}
$$

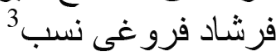

$$
\begin{aligned}
& 3 \text { كارشناس ارشد مهندسى في ايمنى، دانشعاه علوم يزشكى } \\
& \text { شهيد بهشتى تهران، ايران. }
\end{aligned}
$$

$$
\begin{aligned}
& \text { هدف از اين مطالعه ريشه يابى علل رخداد حوادث جاده ايى }
\end{aligned}
$$

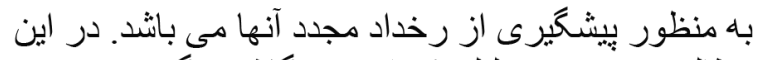

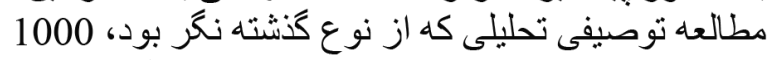

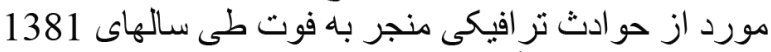

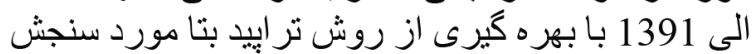

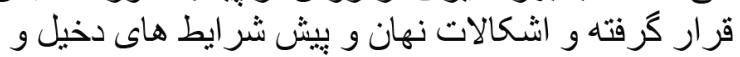

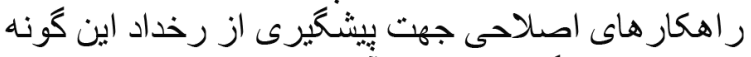

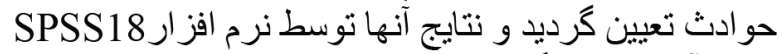

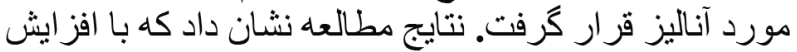

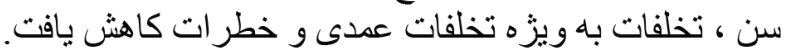

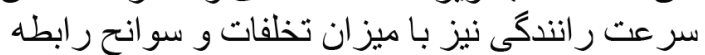

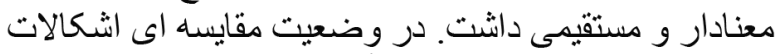

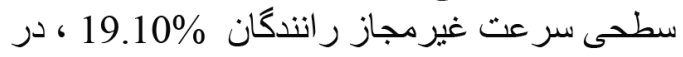

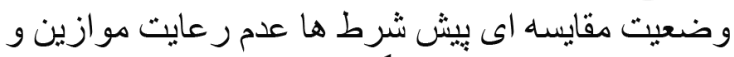

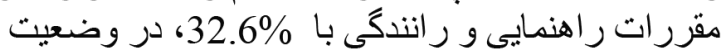

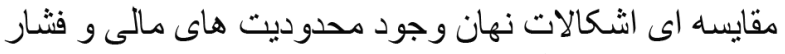

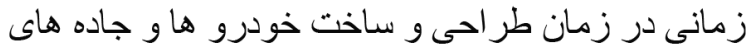

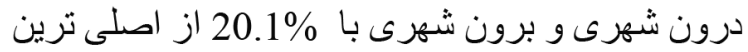

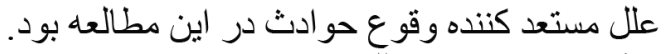

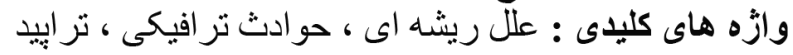

\section{REFERENCES}

[1] Van Beeck E, Mackenbach JP, Looman CW, Kunst AE. Determinants of traffic accident mortality in the Netherlands: a geographical analysis. International journal of epidemiology. 1991;20(3):698-706.

[2] Peden M, Scurfield R, Sleet D, Mohan D, Hyder AA, Jarawan E, Mathers C. World Report on Road Traffic Injury Prevention. Geneva. Switzerland: World Health Organization; 2004.

[3] Bener A. Alwash, R. A perspective on motor vehicle crash injuries and speeding in the United Arab Emirates. Traffic Injury Prevention. 2002;3(1):61-64.

[4] Hyder AA, Peden M. Inequality and road traffic injuries: call for action. Lancet. 2003;362(9401):2034-2035.

[5] Shams M, Rahimi-Movaghar V. Risky driving behaviors in Tehran, Iran. Traffic Injury Prevention. 2009;10(1):91-94.

[6] Global status report on road safety: time for action. World Health Organization; 2009.

[7] Montazeri A. Road-traffic-related mortality in Iran: a descriptive study. Public Health. 2004;118(2): 110-3.

[8] Yousefzadeh S, Ahmadi Dafchahi M, Mohammadi Maleksari M, Dehnadi Moghadam A, Hemati H, Shabani S. Epidemiology of Injuries and their Causes among Traumatic Patients Admitted into Poursina Hospital, Rasht. Behbood. 2007;11(3):286-95.

[9] World development indicators. Washington DC, international bank for reconstruction and development, the World Bank; 2007.

[10] Shibata A, Fukuda K. Risk factors of fatality in motor vehicle traffic accidents. Accident Analysis \& Prevention.1994;26(3):391-397. 
[11] Katsakiori P, Sakellaropoulos G, Manatakis E. Towards and evaluation of accident investigation methods in terms of their alignment with accident causation models. Safety Science. 2009;47(7):1007-1015.

[12] Mohammad Fam I, Kianfar A, Faridan M. Application of Tripod-Beta Approach and Map - Overlaying Technique to Analyse Occupational Fatal Accidents in a Chemical Industry in Iran. International Journal of Occupational Hygiene. 2011;2(1):30-36.

[13] Sklet S. Comparison of some selected methods for accident investigation. Journal of Hazardous Materials. 2004;111(1-3):29-37.

[14] Sagberg F. Road accidents caused by drivers falling asleep. Accident Analysis \& Prevention. 1999;31(6):639-649.

[15] Blockey PN, Hartley LR. Aberrant driving behaviour: errors and violations. Ergonomics. 1995;38(9): 1759-1771.

[16] Singh SK, Misra A. Road Accident Analysis: A Case Study of Patna City. Urban Transport Journal. 2001;2(2):60-75.

[17] Mesken J, Lajunen T, Summala H. Interpersonal violations, speeding violations and their relation to accident involvement in Finland. Ergonomics. 2002;45(6): 469-483.

[18] Zhou JH, Zhao XC, Wang ZG, Zhu PF, Jian HG, Liu DW, Zhou JL, Lin L. The analysis of epidemiological characteristics of road traffic crashes in mountain city in western China. Chinese Journal of Traumatology. 2003;6(6):355-8.
[19] Norris FH, Matthews BA, Riad JK. Character logical, situational, and behavioural risk factors for motor vehicle accidents: A prospective examination. Accident Analysis \& Prevention. 2000;32(4);505-515.

[20] Elvik R, Christensen P, Amundsen A. Speed and road accidents. TØI Report 740. Institute of Transport Economics, Oslo, 2004.

[21] Ahmadi, S. An Investigation of the Effect of Vehicle on Driving Offenses. Traffic Management Studies. 2010; 5(17): 73-82.

[22] Iversen H, Rundmo T. Personality, Risky Driving and Accident Involvement among Norwegian Drivers. Personality and Individual Differences. 2002;33(8): 1251-1263.

[23] Shruthi P, Venkatesh VT, Viswakanth B, Ramesh C, Sujatha PL, Dominic IR. Analysis of Fatal Road Traffic Accidents in a Metropolitan City of South India. Journal of Indian Academy of Forensic Medicine. 2013;35(4):317-320.

[24] Ricci G, Majori S, Mantovani W, Zappaterra A, Rocca G, Buonocore F. Prevalence of alcohol and drugs in urine of patients involved in road accidents. Journal of Preventive Medicine and Hygiene. 2008;49(2):89-95.

[25] Dipak Kumar D. Study of Road Traffic Accidental (RTA) Deaths in and around Barpeta District: An Autopsy Based Study. Journal of Evidence based Medicine and Healthcare. 2015;2(22):3329-3337.

[26] Mohan, D. Road accidents in India. IATSS research. 2009;33(1):75-79. 